\title{
Prevalence and Correlates of Mycoplasma genitalium Infections among Patients Attending a Sexually Transmitted Infection Clinic in Guangdong, China a Cross-sectional Study
}

\section{Xiaohui Zhang}

Guangdong Provincial Dermatology Hospital

\section{PZ Zhao}

Guangdong Provincial Dermatology Hospital

WJ Ke

Guangdong Provincial Dermatology Hospital

\section{LY Wang}

Guangdong Provincial Dermatology Hospital

\section{Lai Sze Tso}

Massachusetts Institute of Technology

\section{ZY Chen}

Guangdong Provincial Dermatology Hospital

YY Liao

Guangdong Provincial Dermatology Hospital

\section{Liang}

Guangdong Provincial Dermatology Hospital

HR Chen

Guangdong Provincial Dermatology Hospital

XQ Ren

Guangdong Provincial Dermatology Hospital

JM Huang

Guangdong Provincial Dermatology Hospital

\section{JJ Ong}

Monash University

\section{F Yang}

University of North Carolina at Chapel Hill

Ligang Yang ( $\sim$ yanglg3@hotmail.com )

Southern Medical University https://orcid.org/0000-0002-6775-8970 


\section{Research article}

Keywords: Prevalence, Mycoplasma genitalium, risk factor

Posted Date: August 12th, 2020

DOI: https://doi.org/10.21203/rs.2.23186/v2

License: (c) (i) This work is licensed under a Creative Commons Attribution 4.0 International License.

Read Full License

Version of Record: A version of this preprint was published at BMC Infectious Diseases on July 5th, 2021. See the published version at https://doi.org/10.1186/s12879-021-06349-4. 


\section{Abstract}

Background: Mycoplasma genitalium (MG) causes urogenital tract infections and is associated with reproductive morbidity. Although MG has been reported across many regions and population groups, it is not yet routinely tested for in China. Our study contributes to current research by reporting the prevalence and correlates of MG infection in patients attending a sexually transmitted infection (STI) clinic in Guangdong from Jan 2017-May 2018.

Methods: Urethral (from 489 men) and endo-cervical (from 189 women) samples, blood samples, and patient histories (via questionnaires) were collected. Doctors clinically diagnosed anogenital warts (GW) during the examination $(n=678)$. The presence of $M G$ was evaluated using an in-house via polymerase chain reaction protocol. We also tested all participants for herpes simplex virus-2 (HSV-2), Neisseria gonorrhoeae (NG), Chlamydia trachomatis (CT), syphilis and HIV. Univariate and multivariate logistic regression were used to evaluate factors associated with MG.

Results: MG was detected in $7.2 \%$ (49/678) of the patients (men, $7.4 \%$; women, $6.9 \%$ ). The MG positivity rate was $14.2 \%$ among symptomatic patients, and $5.6 \%$ for asymptomatic patients, respectively. Only $36.7 \%$ (18/49) Mg positive patients were symptomatic. Among the MG-infected patients, $10.2 \%$ were coinfected with CT, $6.1 \%$ with NG, $8.2 \%$ with HSV-2, $4.1 \%$ with syphilis and $22.4 \%$ with GW. Presentation with clinical symptoms was significantly associated with MG infection [OR=2.52 (2.03-3.13)]. In our analysis, MG was not associated with other STIs.

Conclusions: MG is a relatively common infection among individuals attending an STI clinic in Guangdong Province. Routine testing of symptomatic patients may be necessary, and more epidemiological studies are needed to provide evidence for future testing guidelines,

\section{Introduction}

Mycoplasma genitalium (MG), first isolated from urethral specimens of two men with non-gonococcal urethritis in 1981 [1], is the smallest free-living and self-replicating sexually transmitted pathogen [2]. Since this initial discovery, MG has been identified as a cause of acute and persistent non-gonococcal urethritis (NGU) [3] and cervicitis and is associated with prostatitis [4], balanoposthitis [5], proctitis [6-8] pelvic inflammatory disease (PID) [9], adverse pregnancy outcomes [10], and infertility in both men and women $[11,12]$. MG infection may also increase HIV susceptibility [13].

Some existing epidemiological studies in China suggest that MG is widespread in China. In the available studies of MG infection in men living in China, the positive rate was $3.4 \%$ as detected in first-void urine $(\mathrm{FVU})$ and $5.4 \%$ as detected in the rectal samples of men who have sex with men (MSM) in Shenzhen [14], 15.3\% in the rectal samples of MSM in Shenyang [15]. Among men living with HIV in Jiangsu Province, the positive rate ranged from $20.1 \%$ to $29.2 \%$ as detected in FVU [16-19]. The positive rate of MG was $10.2 \%$ in symptomatic patients with NGU and $13.9 \%$ in patients with asymptomatic NGU in Hong Kong $[20,21]$ and was $28.1 \%$ in men with STD-related complaints in Guangxi [22]. MG prevalence data for 
women are even more limited than those for men. However, one study reported a $13.2 \%$ prevalence in female sex workers living in Jiangsu [23].

In China, MG testing is not routinely performed in most sexually transmitted infection (STI) clinics, as there is no standard MG screening protocol to guide clinical practice, and commercial diagnostic kits were not available until 2019. National prevalence data for MG among routine STI patients are thus lacking. Therefore, we performed a cross-sectional study among patients attending a major urban STI clinic in Guangzhou, Guangdong Province, to assess the prevalence and correlates for MG infection.

\section{Methods}

\section{Study design}

From January 2017 until May 2018, we recruited patients attending our STI clinic in the Dermatology Hospital of Southern Medical University. Because our STI clinic is busy, we invited only patients who went to designated consulting rooms to participate in the study. Only first-time visitors were included in the study, these patients were symptomatic individuals seeking STI screening or asymptomatic individuals seeking STI screening due to high-risk sexual behaviours or having had contact with an infected individual. Patients aged less than 18 years or reporting any systemic antibiotic treatment in the previous 30 days were excluded. After the participants provided informed consent, their sociodemographic characteristics, sexual behaviour data and clinical findings were collected and documented as part of routine clinical procedure.

Sample size

The primary outcome of this study was the prevalence of MG. A previous study reported that the prevalence of MG was $11.2 \%$ [20]; thus, we calculated two-sided confidence intervals for one proportion to estimate a sample size of 651 for this study in order to produce a two-sided $95 \%$ confidence interval with a width of 0.050 .

\section{Pathogen detection}

Urethral swab specimens and FVU at least 2 hours after the last previous urination were collected from all men, including those who reported no symptoms. The urethral swab specimens were used for urethral leucocyte count and MG detection. The urine specimens were tested for Neisseria gonorrhoeae (NG) and Chlamydia trachomatis (CT). Endo-cervical swab specimens were collected from women for MG/NG/CT nucleic acid testing and leucocyte count using microscopy. Blood sera were tested for HIV, Treponema pallidum (TP) and herpes simplex virus 2 (HSV-2) antibodies. 
The amplification assay for MG detection was performed as follows: DNA was extracted using a commercial kit according to the manufacturer's instructions (Daan, Guangzhou, China). MG was detected via TaqMan MGB real-time polymerase chain reaction (PCR) with a sensitivity of five genome equivalents (geq)/reaction, as described by Jensen et al. [24]. Tests for NG and CT were performed using Roche's Cobas 4800 CT/NG test (Roche Diagnostics, Mannheim, Germany). Serum was tested for HIV using two antibody tests-a rapid HIV antibody test (Wantai, Beijing, China) and a second antibody test (Abon Biopharm, Hangzhou, China). If both were positive, another blood sample was collected and sent to the Guangzhou Center for Disease Control and Prevention for confirmation by Western blot analysis (MP Biomedical, Singapore). Serum was tested for syphilis using a toluidine red unheated serum test (TRUST, Rongsheng Bio-technology Limited Corporation, Shanghai, China) and Treponema pallidum particle agglutination (TPPA, Fujirebio Inc, Japan) test. Serum was tested for HSV-2 using the enzyme-linked immunosorbent assay (ELISA) method (Trinity Biotech, Guangzhou, China). Microscopic examination was performed on-site, and other samples were stored at $-20^{\circ} \mathrm{C}$ before testing.

\section{Measures}

Patients were considered symptomatic if they self-reported symptoms, such as dysuria, urethral pruritus ,vaginal discharge, vaginal bleeding after sexual contact, and/or had abnormal findings during physical examination, such as urethral discharge (for males), abnormal vaginal discharge $r$ yellowish mucopurulent $t$ discharge at the cervical os and/or contact bleeding of the cervix (for females).

The urethral smear was regarded as presence of excess leucocytes when $\geq 5$ polymorpho- nuclear leucocytes (PMNL) were seen per high power field (HPF) ( $\times 1000)$ in $\geq 5$ HPF, and the cervical smear was regarded as presence of excess leucocytes when $>30$ PMNL were seen per HPF. Patients with positive TRUST and TPPA tests were considered to have an active syphilis infection unless there was a documented history of previously treated syphilis. Patients with positive HIV screening and confirmatory tests were considered to have HIV infection. Anogenital warts (GW) and anogenital herpes (GH) were diagnosed according to the diagnostic criteria for China's "National Notifiable Disease Reporting System" (Version 2008). These diagnoses were based mainly on exposure history and consistent clinical findings.

\section{Ethics approval}

The study was approved by the Ethics Committee of the Dermatology Hospital of Southern Medical University (approval no. GDDHLS-201502, 31/03/2015). Oral informed consent was obtained from all study participants prior to inclusion in the study.

\section{Statistical analysis}


All data were entered into EpiData 3.0 via double entry for statistical analysis. Descriptive analyses were conducted on the patients' demographic characteristics and the prevalence of MG and other STIs. Categorical variables are presented as numerical and percentage values. Continuous variables are expressed as values if the data were normally distributed and as median (P25 P75) values if the data were non-normally distributed. The chi-square test was used to compare categorical variables between MG-positive and MG-negative participants. Univariate analysis was used to evaluate factors associated with MG. A multivariate logistic regression model with stepwise variable selection was used to evaluate factors associated with MG based on the variables with a P-value of less than 0.1 in univariate analyses. For all analyses in this study, the results are reported as statistically significant when $P \leq 0.05$. All data were analysed using SAS 9.4 (Statistics Analysis Systemint., Cary, NC, USA).

\section{Results}

\section{Characteristics of the study participants}

During the 17-month study period, 727 individuals were recruited, 49 of whom were excluded due to missing data. A total of 678 patients-489 (72\%) men and 189 (28\%) women-were finally included in the present study. The mean age of the study population was $34.02 \pm 13.39$ years $(33.70 \pm 9.23$ years for the men and $34.83 \pm 20.35$ years for the women. Of the 489 men, 41 (6\%) identified as gay and 8 (1\%) as bisexual. None of the women identified themselves as lesbian or bisexual. Half of the participants were married, and 66\% had completed higher education. Most (77\%) had been living in Guangzhou for more than six months.

Among the 678 participants, 127 (14.2\%) were symptomatic; 15.9\% (108/678) of these were men, and 2.8\% (19/678) were women. Other patient characteristics and MG test results are shown in Table 1.

Table 1. Demographic and behavioural characteristics of study participants attending the hospital STI clinic in Guangzhou, $(n=678)$ 


\begin{tabular}{|c|c|c|c|}
\hline Characteristics & Total & $\begin{array}{c}\text { MG positive n (\%) (percentage of individuals with the } \\
\text { characteristic) }\end{array}$ & $\begin{array}{c}P \\
\text { value }\end{array}$ \\
\hline Sex & & & 0.827 \\
\hline Male & 489 & $36(7.36,5.04-9.68)$ & \\
\hline Female & 189 & $13(6.88,3.24-10.52)$ & \\
\hline Age (years) & & & 0.158 \\
\hline $18-25$ & 136 & $15(11.03,5.70-16.36)$ & \\
\hline $26-45$ & 474 & $30(6.33,4.13-8.53)$ & \\
\hline$>45$ & 68 & $4(5.88,0.15-11.62)$ & \\
\hline Marital status & & & 0.264 \\
\hline Single & 309 & $23(7.44,4.50-10.39)$ & \\
\hline Currently married & 342 & $22(6.43,3.822-9.05)$ & \\
\hline Other & 27 & $4(14.81,0.49-29.14)$ & \\
\hline Time at local residence & & & 0.258 \\
\hline $\begin{array}{l}\text { Less than } 6 \text { months } \\
\text { More than } 6 \text { months }\end{array}$ & $\begin{array}{l}155 \\
523\end{array}$ & $\begin{array}{c}8(5.16,1.64-8.68) \\
41(7.83,5.53-10.15)\end{array}$ & \\
\hline Education level & & & 0.329 \\
\hline Middle school or less & 119 & $5(4.20,0.54-7.86)$ & \\
\hline Senior school & 109 & $8(7.34,2.37-12.31)$ & \\
\hline $\begin{array}{l}\text { Secondary school or junior } \\
\text { college }\end{array}$ & 203 & $13(6.40,3.00-9.80)$ & \\
\hline $\begin{array}{l}\text { Bachelor's degree or } \\
\text { higher }\end{array}$ & 247 & $23(9.31,5.66-12.96)$ & \\
\hline Sexual orientation & & & 0.377 \\
\hline Heterosexual & 629 & $47(7.47,5.41-9.53)$ & \\
\hline MSM & 49 & $2(4.08,0.00-9.82)$ & \\
\hline Condom use in $\mathrm{P} 6 \mathrm{~m}$ & & & 0.035 \\
\hline Always & 76 & $1(1.32,0.00-3.94)$ & \\
\hline $\begin{array}{l}\text { Not always } \\
\text { Sexual partners in }{ }^{*} \mathrm{P} 6 \mathrm{~m}\end{array}$ & 602 & $48(7.97,5.80-10.14)$ & 0.474 \\
\hline $\begin{array}{l}0-1 \\
2 \sim 3\end{array}$ & $\begin{array}{l}368 \\
262\end{array}$ & $\begin{array}{l}23(6.25,3.77-8.73) \\
21(8.02,4.71-11.32)\end{array}$ & \\
\hline$>3$ & 48 & $5(10.42,1.45-19.38)$ & \\
\hline${ }^{* *}$ Symptomatic & & & 0.001 \\
\hline No & 551 & $31(5.63,3.70-7.56)$ & \\
\hline Yes & 127 & $18(14.17,8.02-20.32)$ & \\
\hline
\end{tabular}

\section{MG prevalence among and clinical characteristics of the infected patients}

MG was detected in $7.2 \%(49 / 678)$ of all patients in the study, corresponding to a prevalence of $7.4 \%$ (36/489) among men and to 6.9\% (13/189) among women. Mg was more likely to be detected among symptomatic patients, the MG positivity rate was $14.2 \%$ among symptomatic patients, and 5.6\% for asymptomatic patients , respectively.

Among patients with MG infection, only 36.7\% (18/49) were symptomatic, of whom $50.0 \%$ (9/18) were co-infected with CT and/or NG. For detailed clinical manifestations, $16.7 \%$ male patients with $\mathrm{Mg}$ infection had abnormal physical examination findings,47.2\% 
had self-reported symptoms, 33.3\% presented with excess leucocytes with microscopic examinations. For female patients with $\mathrm{Mg}$ infection, the rates for abnormal physical examination findings, self-reported symptoms and presented with excess leucocytes under microscopic examinations were $0 \%, 15,5 \%, 53.8 \%$, respectively. Clinical manifestations of Mg infected patients with or without other infections are shown in Table 2.

Table 2. Clinical manifestations of patients with MG who were coinfected with CT and/or NG , $(n=49)$

\begin{tabular}{|c|c|c|c|c|c|c|}
\hline & & $\begin{array}{l}\mathrm{a}_{\mathrm{MG}} \\
(\%)\end{array}$ & $\begin{array}{c}\mathrm{b}_{\mathrm{CT} \& \mathrm{MG}} \\
(\%)\end{array}$ & $\begin{array}{c}\mathrm{C}_{\mathrm{NG}} \& \mathrm{MG} \\
(\%)\end{array}$ & $\begin{array}{c}\mathrm{d}_{\mathrm{NG} \& C T \& M G} \\
(\%)\end{array}$ & $\begin{array}{c}\text { Total } \\
(\%)\end{array}$ \\
\hline \multicolumn{7}{|l|}{ Men $(n=36)$} \\
\hline \multirow{2}{*}{$\begin{array}{l}\text { Physical examination } \\
\text { findings }\end{array}$} & No & 27 & $2(6.7)$ & $1(5.3)$ & $0(0)$ & \multirow{6}{*}{$\begin{array}{c}30 \\
(83.3) \\
6 \\
(16.7) \\
19 \\
(52.8) \\
17 \\
(47.2) \\
24 \\
(66.7) \\
12 \\
(33.3)\end{array}$} \\
\hline & Yes & $3(50)$ & $0(0)$ & $2(33.3)$ & 1 (16.7) & \\
\hline \multirow[t]{2}{*}{ Self-reported symptoms } & No & \multirow{4}{*}{$\begin{array}{c}17 \\
(89.5) \\
13 \\
(76.5) \\
24 \\
(100) \\
6(50)\end{array}$} & $1(5.3)$ & $1(5.3)$ & $0(0)$ & \\
\hline & Yes & & $1(5.9)$ & $2(11.8)$ & $1(5.9)$ & \\
\hline \multirow{2}{*}{$\begin{array}{l}\text { Presence of excess } \\
\text { leucocytes }\end{array}$} & No & & $0(0)$ & $0(0)$ & $0(0)$ & \\
\hline & Yes & & $2(16.7)$ & $3(25)$ & $1(8.3)$ & \\
\hline \multicolumn{7}{|l|}{ Women $(n=13)$} \\
\hline $\begin{array}{l}\text { Physical examination } \\
\text { findings }\end{array}$ & No & $\begin{array}{c}10 \\
(76.9)\end{array}$ & $3(23.1)$ & $0(0)$ & $0(0)$ & \multirow{5}{*}{$\begin{array}{c}13 \\
(100) \\
0(0) \\
11 \\
(84.6) \\
2 \\
(15.4) \\
6 \\
(46.2) \\
7 \\
(53.8) \\
\end{array}$} \\
\hline \multirow[t]{2}{*}{ Self-reported symptoms } & $\begin{array}{l}\text { Yes } \\
\text { No }\end{array}$ & $\begin{array}{c}0(0) \\
9 \\
(81.8)\end{array}$ & $\begin{array}{c}0(0) \\
2(18.2)\end{array}$ & $\begin{array}{l}0(0) \\
0(0)\end{array}$ & $\begin{array}{l}0(0) \\
0(0)\end{array}$ & \\
\hline & Yes & $1(50)$ & $1(50)$ & $0(0)$ & $0(0)$ & \\
\hline \multirow{2}{*}{$\begin{array}{l}\text { Presence of excess } \\
\text { leucocytes }\end{array}$} & No & $6(100)$ & $0(0)$ & $0(0)$ & $0(0)$ & \\
\hline & Yes & $\begin{array}{c}4 \\
(57.1) \\
\end{array}$ & $3(42.9)$ & $0(0)$ & $0(0)$ & \\
\hline
\end{tabular}

a: $M G$ infection; $b$ : Chlamydia trachomatis infection; $c$ : Neisseria gonorrhoeae infection; $d$ : Chlamydia trachomatis and Neisseria gonorrhoeae infection

The data for co-infections in patients with MG infection are shown in Tables 2 and 3. According to our data, $10.2 \%$ of the patients were co-infected with CT (5/49), 6.1\% with NG 
(3/49), 2.0\% with both CT and NG (1/49), 8.2\% with HSV-2 (4/49), 4.1\% with TP $(2 / 49)$ and $22.4 \%$ with GW $(11 / 49)$.

Table 3. STI infections in patients with and without MG infection, ( $n=678)$

\begin{tabular}{lccc}
\hline $\mathrm{a}_{\text {STI }}$ & MG-negative & MG-positive & $P$ value \\
\hline $\mathrm{b}_{\mathrm{HIV}}$ & & & 0.427 \\
$\mathrm{No}$ & $821(92.7)$ & $49(7.3)$ & \\
Yes & $8(100.0)$ & $0(0.0)$ & 0.802 \\
${ }^{\mathrm{C}} \mathrm{CT}$ & $544(92.7)$ & $43(7.3)$ & \\
No & $85(93.4)$ & $* 6(6.6)$ & \\
Yes & & & 0.250 \\
$\mathrm{~d}_{\text {HSV-2 }}$ & $540(92.3)$ & $45(7.7)$ & \\
No & $88(95.7)$ & $4(4.3)$ & \\
Yes & & & 0.879 \\
$\mathrm{e}_{\text {TP }}$ & $606(92.8)$ & $47(7.2)$ & \\
No & $23(92.0)$ & $2(8.0)$ & 0.271 \\
Yes & & & \\
Genital warts & $441(92.1)$ & $38(7.9)$ & \\
No & $188(94.5)$ & $11(5.5)$ & 0.890 \\
Yes & & & \\
$\mathrm{f}_{\text {NG }}$ & $574(92.7)$ & $45(7.3)$ & \\
No & $55(93.2)$ & $* 4(6.8)$ & \\
Yes & & & \\
& & & \\
\hline
\end{tabular}

a Sexually transmitted infection; ${ }^{\text {b }}$ Human immunodeficiency virus; ${ }^{\mathrm{c}}$ Chlamydia trachomatis;

${ }^{\mathrm{d}}$ Herpes simplex virus 2; ${ }^{\mathrm{e}}$ Treponema pallidum; ${ }^{\mathrm{f}}$ Neisseria gonorrhoeae. * One patient had MG\&CT\&NG coinfection.

\section{Infection rates for other STIsamong the study subjicts}

The infection rates of the other STIs among the study subjects were as follows: CT, $13.4 \%$ (91/678); NG, 8.8\% (59/678); HSV-2, 13.7\% (92/678); GW, 29.4\% (199/678); and HIV, $1.2 \%$ (8/678). Twenty-seven patients were co-infected with MG and one other STI. Sixteen patients were co-infected with MG and more than one other STI. The detailed data are shown in Table 3. 


\section{Correlates of MG infections}

Univariate logistic regression showed that symptomatic patients had a higher MG infection rate than asymptomatic patients $(P=0.001)$. Furthermore, patients who reported not using a condom during all sexual encounters were more likely to be infected with MG than patients who reported using a condom during each sexual encounter in the past 6 months $(P=0.035)$. Multivariable logistic regression showed that only clinical symptoms were associated with MG infection (Table 4). However, MG infection was not associated with other STIs, according to our analysis (Table 3).

Table 4. Regression analysis for factors associated with MG infection in Guangzhou, China, 2017-2018 ( $\mathrm{n}=678)$ 


\begin{tabular}{|c|c|c|c|c|}
\hline & \multicolumn{4}{|c|}{ MG } \\
\hline & Univariate $O R$ & $P$ value & Multivariate $O R$ & $P$ value \\
\hline \multicolumn{5}{|l|}{ Sex } \\
\hline Male & Ref & & & \\
\hline Female & $0.93(0.48-1.79)$ & 0.827 & & \\
\hline \multicolumn{5}{|l|}{ Age (years) } \\
\hline $18-25$ & $1.98(0.632-6.23)$ & 0.241 & & \\
\hline $\begin{array}{l}26-45 \\
>45\end{array}$ & $\begin{array}{c}1.08(0.37-3.17) \\
\text { Ref }\end{array}$ & 0.887 & & \\
\hline \multicolumn{5}{|l|}{ Marital status } \\
\hline Single & Ref & & & \\
\hline Currently married & $0.855(0.47-1.57)$ & 0.612 & & \\
\hline Other & $2.16(0.69-6.79)$ & 0.186 & & \\
\hline \multicolumn{5}{|l|}{ Time at local residence } \\
\hline Less than 6 months & Ref & & & \\
\hline More than 6 months & $1.52(0.73-3.17)$ & 0.258 & & \\
\hline \multicolumn{5}{|l|}{ Education level } \\
\hline Middle school or less & Ref & & & \\
\hline Senior school & $1.81(0.57-5.69)$ & 0.313 & & \\
\hline Secondary school or junior college & $1.56(0.54-4.49)$ & 0.409 & & \\
\hline Bachelor's degree or higher & $2.34(0.87-6.32)$ & 0.093 & & \\
\hline \multicolumn{5}{|l|}{ Sexual orientation } \\
\hline Heterosexual & $1.90(0.45-8.06)$ & 0.377 & & \\
\hline MSM & Ref & & & \\
\hline \multicolumn{5}{|l|}{ Condom use in Past $6 \mathrm{~m}$} \\
\hline Always & Ref & & & \\
\hline Not always & $6.50(1.11-8.66)$ & 0.035 & & \\
\hline \multicolumn{5}{|l|}{ Sexual partner in Past $6 \mathrm{~m}$} \\
\hline $0-1$ & Ref & & & \\
\hline $2 \sim 3$ & $1.31(0.71-2.42)$ & 0.393 & & \\
\hline$>3$ & $1.74(0.63-4.83)$ & 0.284 & & \\
\hline \multicolumn{5}{|l|}{ Clinical symptoms } \\
\hline No & Ref & & Ref & \\
\hline Yes & $2.52(2.03-3.13)$ & 0.001 & $2.52(2.03-3.13)$ & 0.001 \\
\hline
\end{tabular}

\section{Discussion}

In our study, the prevalence of MG among patients attending our STI clinic was $7.2 \%$ (7.4\% men, $6.9 \%$ women), and $36.7 \%$ of patients with MG infection were symptomatic. Among symptomatic patients, the prevalence of MG was $14.17 \%$ (18/127, 16 were men). Presentation with clinical symptoms was significantly associated with MG infection [OR=2.52 (2.03-3.13)].

Limitations of our study included the inability to recruit larger numbers of female patients and the small number of individuals with MG. Moreover, the patients were recruited from one hospital, and the results may thus not be generalizable to all patient populations in China.

The prevalence rates $(7.2 \%, 7.4 \%$, respectively) among all patients and men attending our clinic were higher than those among patients attending STI clinics with symptoms of urogenital tract infections or for a check-up in Greece (5.7\%,6.4\%, respectively) [25] and Norway (4.9\%, 4.5\%, respectively) [26] but 
lower than the corresponding rates in Denmark (9.0\%, 8.9\%, respectively) [26], Sweden $(9.8 \%, 9.1 \%$, respectively) [26] and the US (16.7\%, 17.2\%, respectively) [27]. The MG prevalence among men with symptoms were $14.2 \%(18 / 127)$ in our study, $12.3 \%$ in a study in London [28] and $16.7 \%$ in a study in Brussels [29] The MG prevalence in women in our study was $6.9 \%$ (95\% Cl: $3.2 \%-10.5 \%)$, similar to the rates in women attending STI clinics with symptoms of urogenital tract infections or for a check-up in Greece (6.9\%) [25] and Norway (6.0\%) [26] but lower than the corresponding rates in Denmark (9.3\%) [26], Sweden (11.1\%) [26] and in two studies in the US $(16.3 \%, 17.5 \%)[27,30]$.

In our study, symptomatic patients were more likely to have MG infection than asymptomatic individuals (14.2\% vs. $5.6 \%, P=0.001)$. This pattern was also reported for men but not women among patients attending a young person's clinic in Sweden [31]. However, some studies arrived at the opposite conclusions, i.e., finding no statistical association between clinical symptoms and MG infection in men attending an STI clinic in Guangxi Province, China [22], and no association between MG infection and microscopically defined urethritis or cervicitis in patients in Greece [25]. These different conclusions may be related to the composition of the sample and the definition of symptoms.

In studies from Greece [25], Kenya [32] and Honduras [33], consistent condom use was not protective against MG. In our study, in the univariate analysis, patients who reported not using a condom during all sexual encounters in the past 6 months were more likely to be infected with MG than patients who reported using condom during each sexual encounter in the past 6 months $(P=0.035)$, while the multivariate analysis result failed to verify the linkage between protection of $\mathrm{Mg}$ infection and condom use.

Consistent with previous findings from the UK [28] and Greece [34], no association of MG infection with other STIs was found in our study via the chi-square test, indicating that MG might be an independent pathogen in the genital tract. The high level of MG and CT/NG co-infection suggests that screening and treating CT may not greatly impact MG infection, since azithromycin $(1 \mathrm{~g})$, the first-line drug for treating CT infection, appears to be a suboptimal choice for MG treatment.

In conclusion, MG was one the most common pathogen causing infection in individuals attending an STI clinic in Guangdong (7.2\%). MG was an independent infection, and symptomatic patients were more likely than asymptomatic patients to be infected. Improving the accessibility of $\mathrm{Mg}$ testing in STI clinics in Guangdong Province is necessary, and more epidemiological studies are needed to provide evidence for future testing guidelines,

\section{List Of Abbreviations}

MG Mycoplasma genitalium

STI sexually transmitted infection

GW genital warts 
HSV herpes simplex virus

NG Neisseria gonorrhoeae

CT Chlamydia trachomatis

\section{Declarations}

\section{Ethics approval and consent to participate}

The study was approved by the Ethics Committee of the Dermatology Hospital of Southern Medical University (approval no. GDDHLS-201502, 31/03/2015). Oral informed consent was obtained from all study participants prior to inclusion in the study.

\section{Consent for publication}

Not applicable.

\section{Availability of data and materials}

The data sets generated and/or analysed during the current study are available from the corresponding author upon reasonable request.

\section{Competing interests}

The authors declare that they have no competing interests.

\section{Funding}

This work was supported by research funds from the Bureau of Science and Information Technology of Guangzhou Municipality (201704020219), Guangdong Provincial Medical Science and Technology (A2018346 and B2018124), Southern Medical University (C1034403) and the Research Council of Norway (grant ID number 275002).

\section{Authors' contributions}


Yang LG designed the research. Zhang XH, Ke WJ, Wang LY, Chen ZY, Liao YY, Liang CM, Chen HR, Ren XQ and Yang LG completed the questionnaire and collected the clinical samples from all patients. Zhang PZ analysed and interpreted the patient data. Zhang XH was a major contributor to manuscript writing. Ke WJ, Wang LY and Lai Sze Tso assisted with manuscript writing. Huang JM performed the laboratory test for the pathogens. Yang LG, Ong JJ and Yang F reviewed the manuscript. All authors read and approved the final manuscript.

\section{Acknowledgements}

The study team would like to thank all participants who participated in the study.

\section{Authors' information}

\section{References}

1. Tully J, Cole R, Taylor-Robinson D, Rose D. A newly discovered mycoplasma in the human urogenital tract. Lancet. 1981;317:1288-91.

2. Dorman CJ. Regulation of transcription by DNA supercoiling in Mycoplasma genitalium: global control in the smallest known self-replicating genome. Mol Microbiol. 2011;81:302-4.

3. Horner PJ, Gilroy CB, Thomas BJ, Taylor-Robinson D, Horner PJ, Gilroy CB, et al. Association of Mycoplasma genitalium with acute non-gonococcal urethritis. Lancet. 1993;342:582-5.

4. Mo X, Zhu C, Gan J, Wang C, Wei F, Gong W, et al. Prevalence and correlates of Mycoplasma genitalium infection among prostatitis patients in Shanghai, China. Sex Health. 2016;13:474.

5. Horner PJ, Taylor-Robinson D. Association of Mycoplasma genitalium with balanoposthitis in men with non-gonococcal urethritis. Sex Transm Infect. 2010;87:38-40.

6. Horner PJ, Martin DH. Mycoplasma genitalium infection in men. J Infect Dis. 2017;216:S396-405.

7. Papeš D, Pasini M, Jerončić A, Vargović M, Kotarski V, Markotić A, et al. Detection of sexually transmitted pathogens in patients with chronic prostatitis/chronic pelvic pain: a prospective clinical study. Int J STD AIDS. 2017;28:613-5.

8. Ong JJ, Aung E, Read TRH, Fairley CK, Garland SM, Murray G, et al. Clinical characteristics of anorectal Mycoplasma genitalium infection and microbial cure in men who have sex with men. Sex Transm Dis. 2018;45:522-6. 
9. Bjartling C, Osser S, Persson K. Mycoplasma genitalium in cervicitis and pelvic inflammatory disease among women at a gynecologic outpatient service. Am J Obstet Gynecol. 2012;206:476.e1-8.

10. Ona S, Molina RL, Diouf K. Mycoplasma genitalium: an overlooked sexually transmitted pathogen in women? Infect Dis Obstet Gynecol. 2016;2016:4513089.

11. Grześko J, Elias M, Maczyńska B, Kasprzykowska U, Tłaczała M, Goluda M. Occurrence of Mycoplasma genitalium in fertile and infertile women. Fertil Steril. 2009;91:2376-80.

12. Svenstrup HF, Fedder J, Abraham-Peskir J, Birkelund S, Christiansen G. Mycoplasma genitalium attaches to human spermatozoa. Hum Reprod 2003;18:2103-9

13. Napierala Mavedzenge S, Weiss HA. Association of Mycoplasma genitalium and HIV infection: a systematic review and meta-analysis. AIDS. 2009;23:611-20.

14. Zheng BJ, Yin YP, Han Y, Shi MQ, Jiang N, Xiang Z, et al. The prevalence of urethral and rectal Mycoplasma genitalium among men who have sex with men in China, a cross-sectional study. BMC Public Health. 2014;14:195.

15. Zhao N, Li KT, Gao YY, Xu JJ, Huang DS. Mycoplasma Genitalium and Mycoplasma hominis are prevalent and correlated with HIV risk in MSM: a cross-sectional study in Shenyang, China. BMC Infect Dis. 2019;19:494.

16. Chen LS, Wu JR, Wang B, Yang T, Yuan R, Zhao YY, et al. Epidemiology of Mycoplasma acquisition in male HIV-1 infected patients: a multistage cross-sectional survey in Jiangsu, China. Epidemiol Infect. 2015;143:3327-34.

17. Jian-Ru W, Bei W, Hao C, Jin-Shui X, Xi-Ping H. Mycoplasmas in the urine of HIV-1 infected men. Epidemiol Infect. 2011;140:1141-6.

18. Wu JR, Wang B, Zhou LJ, Xie YX, Xu JS, Chen LS, et al. Mycoplasmas infection in male HIV/AIDS patients in Jiangsu, China. Microb Pathog. 2013;63:54-8.

19. Wu JR, Wang B, Chen LS, Yang T, Zhou LJ, Xie YX, et al. Alarming incidence of genital mycoplasmas among HIV-1-infected MSM in Jiangsu, China. Eur J Clin Microbiol Infect Dis. 2014;33:189-95.

20. Yu JT, Tang WY, Lau KH, Chong LY, Lo KK, Wong CK, et al. Role of Mycoplasma genitalium and Ureaplasma urealyticum in non-gonococcal urethritis in Hong Kong. Hong Kong Med J. 2008;14:125-9.

21. Yu JTHT, Tang WYM, Lau KH, Chong LY, Lo KK. Asymptomatic urethral infection in male sexually transmitted disease clinic attendees. Int J STD AIDS. 2008;19:155-8.

22. Zheng BJ, Yin YP, Xiang Z, Han Y, Shi MQ, Jiang N, et al. An epidemiological study of Mycoplasma genitalium infections among males attending a sexually transmitted disease clinic in Guangxi, China. 
Jpn J Infect Dis. 2014;67:17-21.

23. Yin YP, Li HM, Xiang Z, Liang GJ, Shi MQ, Zhou YJ, et al. Association of sexually transmitted infections with high-risk human papillomavirus types. Sex Transm Dis. 2013;40:493-5.

24. Jensen JS, Björnelius E, Dohn B, Lidbrink P. Use of TaqMan 5' nuclease real-time PCR for quantitative detection of Mycoplasma genitalium DNA in males with and without urethritis who were attendees at a sexually transmitted disease clinic. J Clin Microbiol. 2004;42:683-92.

25. Chra P, Papaparaskevas J, Papadogeorgaki E, Panos G, Leontsinidis M, Arsenis G, et al. Prevalence of Mycoplasma genitalium and other sexually-transmitted pathogens among high-risk individuals in Greece. Germs. 2018;8:12-20.

26. Unemo M, Salado-Rasmussen K, Hansen M, Olsen AO, Falk M, Golparian D, et al. Clinical and analytical evaluation of the new Aptima Mycoplasma genitalium assay, with data on M. genitalium prevalence and antimicrobial resistance in M. genitalium in Denmark, Norway and Sweden in 2016. Clin Microbiol Infect. 2018;24:533-9.

27. Getman D, Jiang A, O'Donnell M, Cohen S. Mycoplasma genitalium prevalence, coinfection, and macrolide antibiotic resistance frequency in a multicenter clinical study cohort in the United States. J Clin Microbiol. 2016;54:2278-83.

28. Huntington SE, Burns RM, Harding-Esch E, Harvey MJ, Hill-Tout R, Fuller SS, et al. Modelling-based evaluation of the costs, benefits and cost-effectiveness of multipathogen point-of-care tests for sexually transmitted infections in symptomatic genitourinary medicine clinic attendees. BMJ Open.

2018;8:e020394.

29. Libois A, Hallin M, Crucitti T, Delforge M, De Wit S. Prevalence of Mycoplasma genitalium in men with urethritis in a large public hospital in Brussels, Belgium: an observational, cross-sectional study. PLoS One. 2018;13:e0196217.

30. Lillis RA, Martin DH, Nsuami MJ. Mycoplasma genitalium infections in women attending a sexually transmitted disease clinic in new orleans. Clin Infect Dis. 2018;69:459-65.

31. Nolskog P, Backhaus E, Nasic S, Enroth H. STI with Mycoplasma genitalium-more common than Chlamydia trachomatis in patients attending youth clinics in Sweden. Eur J Clin Microbiol Infect Dis. 2018;38:81-6.

32. Gomih-Alakija A, Ting J, Mugo N, Kwatampora J, Getman D, Chitwa M, et al. Clinical characteristics associated with Mycoplasma genitalium among female sex workers in Nairobi, Kenya. J Clin Microbiol. 2014;52:3660-6.

33. Johnston LG, Paz-Bailey G, Morales-Miranda S, Morgan M, Alvarez B, Hickman L, et al. High prevalence of Mycoplasma genitalium among female sex workers in Honduras: implications for the 
spread of HIV and other sexually transmitted infections. Int J STD AIDS. 2012;23:5-11.

34. Ikonomidis A, Venetis C, Georgantzis D, Giaslakiotis V, Kolovos V, Efstathiou K, et al. Prevalence of Chlamydia trachomatis, Ureaplasma spp., Mycoplasma genitalium and Mycoplasma hominis among outpatients in central Greece: absence of tetracycline resistance gene tet( $(\mathrm{M})$ over a 4-year period study. New Microbes New Infect. 2016;9:8-10. 